\title{
Hydroxycinnamic Acid Degradation, a Broadly Conserved Trait, Protects Ralstonia solanacearum from Chemical Plant Defenses and Contributes to Root Colonization and Virulence
}

\author{
Tiffany M. Lowe, ${ }^{1,2}$ Florent Ailloud, ${ }^{3,4}$ and Caitilyn Allen ${ }^{2}$ \\ ${ }^{1}$ Microbiology Doctoral Training Program, and ${ }^{2}$ Department of Plant Pathology, University of Wisconsin-Madison, Madison, \\ WI, U.S.A.; ${ }^{3}$ CIRAD, UMR Peuplements Végétaux et Bioagresseurs en Milieu Tropical, CIRAD-Université de la Réunion, \\ Pôle de Protection des Plantes, Saint Pierre, La Réunion, France; ${ }^{4}$ Anses, Plant Health laboratory, Saint Pierre, La Réunion, \\ France
}

Submitted 30 September 2014. Accepted 15 November 2014.

\begin{abstract}
Plants produce hydroxycinnamic acid (HCA) defense compounds to combat pathogens, such as the bacterium Ralstonia solanacearum. We showed that an HCA degradation pathway is genetically and functionally conserved across diverse $R$. solanacearum strains. Further, a feruloyl-CoA synthetase $(\Delta f c s)$ mutant that cannot degrade HCA was less virulent on tomato plants. To understand the role of HCA degradation in bacterial wilt disease, we tested the following hypotheses: HCA degradation helps the pathogen i) grow, as a carbon source; ii) spread, by reducing HCA-derived physical barriers; and iii) survive plant antimicrobial compounds. Although HCA degradation enabled $\boldsymbol{R}$. solanacearum growth on HCA in vitro, HCA degradation was dispensable for growth in xylem sap and root exudate, suggesting that $\mathrm{HCA}$ are not significant carbon sources in planta. Acetyl-bromide quantification of lignin demonstrated that $R$. solanacearum infections did not affect the gross quantity or distribution of stem lignin. However, the $\Delta f c s$ mutant was significantly more susceptible to inhibition by two HCA, namely, caffeate and $p$-coumarate. Finally, plant colonization assays suggested that $\mathrm{HCA}$ degradation facilitates early stages of infection and root colonization. Together, these results indicated that ability to degrade HCA contributes to bacterial wilt virulence by facilitating root entry and by protecting the pathogen from HCA toxicity.
\end{abstract}

Plants produce thousands of phenolic compounds, which play roles in plant development and interactions with microbes (Mandal et al. 2010; Naoumkina et al. 2010). Among these are hydroxycinnamic acids (HCA), which are monocyclic phenylpropanoid molecules. Roots exude HCA and related phenolics to chelate metals, thereby facilitating uptake and transport of metals in the xylem sap (Ishimaru et al. 2011). In response to root pathogens, many plants release de novo synthesized HCA

Corresponding author: C. Allen; E-mail: cza@plantpath.wisc.edu; Telephone: +1.608 .262 .9578 .

* The $\boldsymbol{e}$-Xtra logo stands for "electronic extra" and indicates that two supplementary tables and one supplementary figure are published online.

(C) 2015 The American Phytopathological Society into the rhizosphere, and grapevines infected with Xylella spp. accumulate HCA and HCA conjugates in their xylem sap (Lanoue et al. 2010; Mandal and Mitra 2008; Wallis and Chen 2012). HCA are broadly antimicrobial; they disrupt membrane integrity and decouple the respiratory proton gradient (Fitzgerald et al. 2004; Harris et al. 2010). Additionally, HCA reinforce protective physical barriers in plants by cross-linking primary cell wall polysaccharides and by serving as precursors for the phenolic polymer lignin (Campos et al. 2014; Fry et al. 2000; Naoumkina et al. 2010).

Plants defend their vascular systems with phenolic-storing cells stationed along the xylem (Beckman 2000). These phenolic-storing cells decompartmentalize in response to infection and release phenolics into the xylem lumen, in a process similar to neutrophil degranulation in animal immunity. Exposing tomato roots to the xylem-dwelling fungal vascular wilt pathogen, Fusarium oxysporum f. sp. lycopersici, leads to increased accumulation of the HCA ferulate and $p$-coumarate (Mandal and Mitra 2008). Ultrastructure studies of xylem infected with the vascular pathogen Ralstonia solanacearum show phenomena consistent with phenolic release (Grimault et al. 1994; Mueller and Beckman 1984; Nakaho et al. 2000; Rahman et al. 1999).

$R$. solanacearum causes bacterial wilt disease, which limits production of key crops such as potato, banana, peanut, and tomato (Elphinstone 2005). This soil-dwelling pathogen generally enters hosts through the roots and then colonizes the xylem elements throughout the plant. Extensive colonization of the xylem ultimately blocks water transport, leading to stunting and wilting. $R$. solanacearum strains form a large, heterogeneous species complex that collectively infects hundreds of different plant species (Peeters et al. 2013).

Several lines of evidence suggest that HCA are involved in tomato interactions with $R$. solanacearum. Quantitative resistance of tomato cultivars against $R$. solanacearum is correlated with early expression of phenylalanine ammonia lyase, which catalyzes the first step in phenylpropanoid biosynthesis (Vanitha et al. 2009). Transcriptomic analysis showed that multiple phenylpropanoid biosynthesis genes are upregulated in $R$. solanacearum-infected, resistant tomato plants compared with healthy plants (Ishihara et al. 2012) (R. Mitra, A. Milling and C. Allen, unpublished). We previously found that drug efflux pumps protect $R$. solanacearum from the toxicity of many plant defense chemicals, including the HCA caffeate (Brown 
et al. 2007). More specifically, the genomes of many $R$. solanacearum strains encode an enzymatic pathway that is homologous to a Pseudomonas fluorescens pathway that breaks down the HCA ferulate, $p$-coumarate, and caffeate to central carbon metabolites (Narbad and Gasson 1998) (Fig. 1). These HCA degradation pathway genes are expressed by $R$. solanacearum cells growing in tomato xylem vessels at the onset of wilt symptoms (Salanoubat et al. 2002; Jacobs et al. 2012).

We explored the hypothesis that HCA degradation contributes to bacterial wilt disease. We found that HCA degradation is widely conserved in the $R$. solanacearum species complex. A feruloyl-CoA synthetase mutant $(\Delta f c s)$ that cannot degrade HCA had reduced virulence on tomato, delayed colonization of tomato roots, and increased susceptibility to the toxicity of the HCA caffeate and $p$-coumarate.

\section{RESULTS}

\section{Organization of HCA degradation genes}

\section{in $R$. solanacearum GMI1000.}

HCA degradation enzymes encoded by the genes $f c s, f c a$, $v d h$, van $A B$, and pobA convert the HCA $p$-coumarate, caffeate, and ferulate to protocatechuate and acetyl-CoA (Fig. 1A). The $\beta$-ketoadipate enzymes encoded by the $p c a$ genes further metabolize protocatechuate to the central carbon metabolites succinyl-CoA and a second acetyl-CoA. In $R$. solanacearum GMI1000, the HCA degradation and $\beta$-ketoadipate genes are organized as five putative operons at three genomic loci (Fig. 1B): $f c a-v d h-f c s$ (RSp0225-0227), vanAB (RSp0222-0223), pobA (RSc02242), pcaGH (RSc1141-1142), and pcaIJFBDC (RSc2249-2255).

We used the orthologous matrix (OMA) browser to investigate the conservation of genes for $\mathrm{HCA}$ and protocatechuate degradation across bacteria (Supplementary Table S2). OMA uses a strict algorithm to categorize orthologous proteins from complete publically available genome sequences (Altenhoff et al. 2011). The eukaryotic $\beta$-ketoadipate genes are not homologous to the bacterial genes; therefore, we did not analyze eukaryotic genomes. OMA analysis indicated that HCA degradation is a rare trait among the 1,281 bacterial strains considered. Many plant-pathogenic bacteria lacked HCA degradation genes, including the necrotroph Dickeya dadantii 3937, which uses feruloyl-esterases to cleave HCA from cell wall polysaccharides (Hassan and Hugouvieux-Cotte-Pattat 2011), and $X y$ lella fastidiosa, which encounters HCA in grapevine xylem (Wallis and Chen 2012). Although the OMA database tends to yield false negatives, we gained insight on the prevalence and distribution of this pathway in bacteria because HCA degradation has been functionally characterized in several of the strains included in the OMA database (Abdelkafi et al. 2006; Campillo et al. 2014; Kim et al. 2008; Parke and Ornston 2003; Pérez-Pantoja et al. 2008; Plaggenborg et al. 2003; RomeroSilva et al. 2013). For example, although OMA analysis indicated that Cupriavidus pinatubonensis JMP134 (formerly $C$. necator and $R$. eutropha) lacks four of $14 \mathrm{HCA}$ degradation genes, this strain is known to degrade HCA. Therefore, we hypothesized that the 33 strains containing more than 10 of 14 HCA degradation genes likely degrade HCA. These strains are predominantly in genera known to spend part of their lifecycles in soil, Burkholderia, Brucella, and Pseudomonas. OMA analysis identified several plant-associated genera that appear to have functional $\beta$-ketoadipate pathways but lack the upstream HCA-degrading enzymes: Xanthomonas campestris, Rhizobium spp., and Agrobacterium spp. (although Campilo and associates [2014] show that Agrobacterium sp. strain C58 degrades HCA).

\section{The HCA degradation pathway is broadly conserved in the $R$. solanacearum species complex.}

Because HCA are common plant metabolites, the ability to degrade these metabolites could benefit $R$. solanacearum. To explore the genetic conservation of the HCA degradation path-

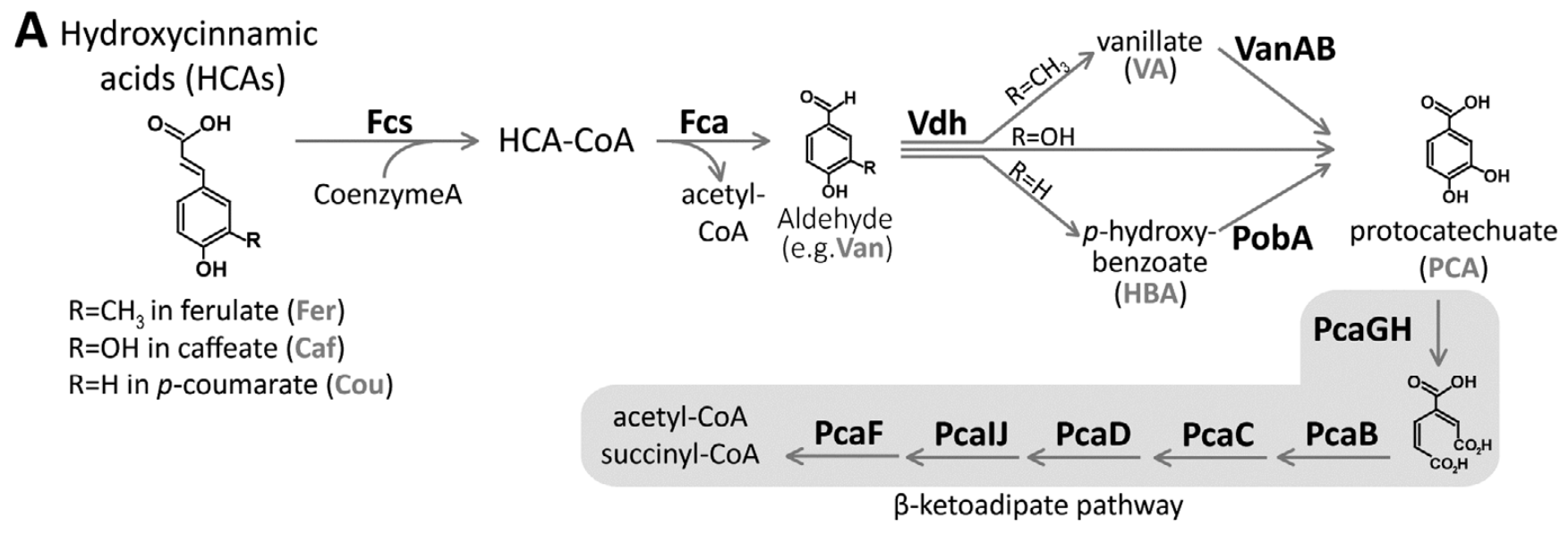

B

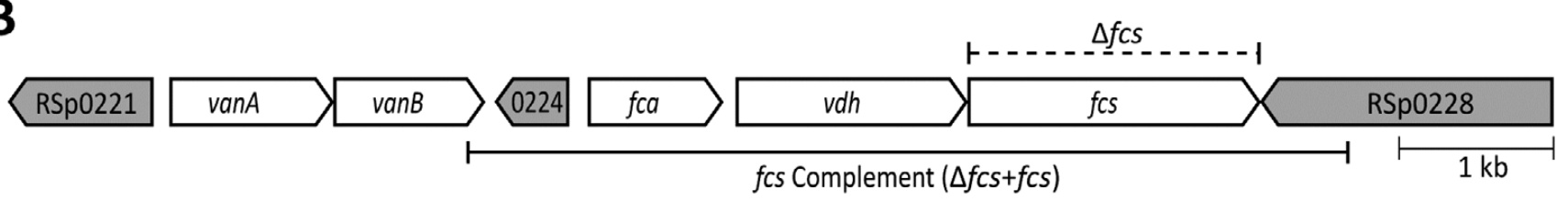

Fig. 1. Hydroxycinnamic acid (HCA) degradation pathway and genes in Ralstonia solanacearum GMI1000. A, The HCA degradation pathway is shown with enzyme names in boldface. Fcs, Fca, and Vdh convert the HCA ferulate, $p$-coumarate, and caffeate to the phenolic acids vanillate, $p$-hydroxybenzoate, and protocatechuate, respectively. VanAB and PobA convert vanillate and $p$-hydroxybenzoate to protocatechuate, which is further metabolized by the $\beta$-ketoadipate enzymes. B, Locus containing genes encoding multiple enzymes in the HCA degradation pathway. White arrows indicate open reading frames (ORF) encoding HCA degradation and gray arrows indicate neighboring ORF. RSp0221, RSp0224, and RSp0228 encode transcriptional regulators of the LysR family, MarR family, and Fis family, respectively. The dashed line above the genes indicates the region that was precisely excised to create the feruloyl-CoA synthetase deletion mutant $(\Delta f c s)$. The solid line below the genes indicates the region used to genetically complement the $\Delta f c s$ mutation in the $\Delta f c s+f c s$ strain. 
way in the large and heterogeneous $R$. solanacearum species complex, we searched for homologs of HCA degradation genes in the genomes of 23 available $R$. solanacearum strains (Fig. 2A; Supplementary Table S1) (Gabriel et al. 2006; Remenant et al. 2010, 2011; and 2012, and Wicker et al. 2007). Only two strains lacked multiple HCA degradation genes: phylotype IIA strain K60 and phylotype IV blood disease bacterium (BDB) strain R229. We identified homologs of each HCA degradation gene in the remaining 21 strains $(91 \%)$ but, in eight of these strains, one or more genes were located on a contig border or were annotated as putative pseudogenes.

The number of potential pseudogenes and genes lying on contig borders made it difficult to predict the HCA degradation ability of a third of the sequenced strains; therefore, we functionally characterized the HCA degradation ability of all available strains. We could not analyze strains Po82, FQY-4, and Y45 because the authors of these published genomes would not share their strains (Cao et al. 2013; Li et al. 2011; Xu et al. 2011). Each strain was tested for its ability to grow on the HCA ferulate and $p$-coumarate as well as on the pathway intermediates vanillin, vanillate, $p$-hydroxybenzoate, and protocatechuate (Fig. 1A). Most strains grew on all tested compounds, except where genomic data indicated an incomplete pathway (Fig. 2A). For example, because it lacks $f c s, f c a, v d h$, vanB, pobA, and pcaH, strain K60 did not grow on any tested substrate. Similarly, BDB strain R229, lacking $f c s, f c a, v d h$, and van $B$, grew only on protocatechuate.

In several cases, bioinformatic data did not accurately predict biological function. Surprisingly, although strains CFBP2957 and Molk2 grew on ferulate, they did not grow on the ferulate degradation intermediates vanillin (in the case of CFPB2957) or vanillin and vanillate (in the case of Molk2). It is possible that higher sensitivity to toxicity of vanillin and vanillate prevented these strains from growing. Several strains with a putatively pseudogenized $f_{c s}$ displayed contrasting growth phenotypes. Although strain UW179 grew on all compounds, the phylotype II sequevar 1 (race 3 biovar 2) strains UW491 and UW551 unexpectedly did not grow on ferulate, $p$-coumarate, vanillin, or vanillate. Further, strains CIP417 and CMR15 grew on intermediate metabolites but not ferulate or $p$-coumarate, even though these strains apparently possess complete sets of HCA degradation genes. Taken together, these analyses indicate that most $R$. solanacearum strains can degrade at least some HCA; the unexpected positive and negative results for growth on HCA also highlight the importance of functional experiments to confirm genomic analyses.

To determine whether HCA degradation contributes to bacterial wilt disease, we created an $f c s$ deletion mutant in the background of phylotype I strain GMI1000. Hereafter, strain GMI1000 is referred to as the wild type (WT) and the GMI1000 deletion mutant lacking the feruloyl-CoA synthetase open reading frame (ORF) is referred to as the $\Delta f c s$ mutant. Whereas the WT used HCA and intermediate phenolics as a carbon source (Fig. 2), the $\Delta f c s$ mutant did not grow on the HCA $p$-coumarate, caffeate, or ferulate, as predicted (Fig. 2B). Additionally, the mutant grew as well as the WT on all pathway intermediates (data not shown). This result confirmed the bioinformatic annotation of this gene and also confirmed the deletion of the $f c s$ gene. Genetic complementation of the mutant with the cloned $f c s$ operon under control of the native promoter restored its growth on HCA (Fig. 2B).

\section{HCA degradation contributes}

to $R$. solanacearum virulence on tomato.

We used a naturalistic soil-soak virulence assay to measure the contribution of HCA degradation to $R$. solanacearum virulence on tomato. Bacterial suspensions were poured into the soil of individually potted unwounded tomato plants, and symptom development was measured over time.

The $\Delta f c s$ mutant displayed a modest but significant reduction in virulence on plants grown at the tropical temperature $28^{\circ} \mathrm{C}$ (Fig. 3A) (repeated measure analysis of variance; $P=$ $0.0123)$. The reduced virulence of the $\Delta f c s$ mutant did not result from an altered rate of symptom progression. Once they became symptomatic, plants inoculated with either strain progressed to end-stage disease at the same rate (average time was 1.2 and 1.1 days for WT- and $\Delta f c s$-inoculated plants, respectively, between the first symptoms and the highest disease index rating $(P=0.402$, unpaired $t$ test $)$. To determine whether the virulence defect was due to a delay in symptom onset, we used survival analysis. Although survival analysis was originally developed to analyze patient outcome data in clinical trials, this statistical tool can analyze any discrete biological events in a time course. This analysis revealed that symptom onset was earlier in WT-inoculated plants than in $\Delta f c s$-inoculated plants (Fig. 3B) (log-rank Mantel-Cox test; $P=0.0118$ ). The median time until symptom onset was 6 days after WT inoculation and 7 days after $\Delta f c s$ mutant inoculation. This result suggested that the virulence defect of the $\Delta f c s$ mutant affects an early stage of the infection process before symptom onset.

Because HCA degradation genes were highly expressed when $R$. solanacearum infected plants at cool temperatures $(\mathrm{F}$. Meng, J. M. Jacobs, and C. Allen, unpublished), we also quantified the virulence of the $\Delta f c s$ mutant in a growth chamber at $24^{\circ} \mathrm{C}$ (day) and $19^{\circ} \mathrm{C}$ (night) (Fig. 3C). Under these cooler conditions, the $\Delta f c s$ mutant also displayed a virulence defect.

\section{HCA degradation is not required for $R$. solanacearum growth in plant-associated environments.}

We hypothesized that HCA degradation contributes to $R$. solanacearum virulence by providing the bacterium with a carbon source in the competitive and nutrient-limited niches in and around plants. Plant roots exude HCA into the rhizosphere, and HCA compose up to $10 \%$ of the water-soluble carbon in soil (Smolander et al. 2005). Thus, the ability to use HCA as a carbon source could provide bacteria with a competitive edge in the soil. We asked whether HCA degradation increased growth of $R$. solanacearum in water-soluble potting soil extract and in root exudate from sterile tomato seedlings. The $\Delta f c s$ mutant grew as well as its WT parent in both substrates (Fig. 4A and B). However, sterile tomato seedlings may produce fewer HCA than mature plants with a diverse microbiome because pathogens induce production and release of HCA into the rhizosphere (Neumann and Römheld 2007). HCA chelate and transport metals in the xylem sap, and concentrations of HCA conjugates increase in grapevines infected with Xylella spp. (Ishimaru et al. 2011; Wallis and Chen 2012). Therefore, we asked whether HCA degradation provides a growth benefit to $R$. solanacearum in xylem sap. Xylem sap was harvested by detopping healthy tomato plants and allowing root pressure to exude the sap. The sap was filter sterilized and used as a growth substrate for WT, $\Delta f c s$, and $\Delta f c s+f c s$ (complemented) bacteria. HCA degradation ability did not affect growth of any strain in healthy xylem sap (Fig. 4C). Because $R$. solanacearum infections induce expression of tomato phenolic biosynthesis genes (Ishihara et al. 2012; R. Mitra, A. Milling, and C. Allen, unpublished), we hypothesized that xylem sap from infected plants contains higher HCA concentrations that would benefit growth of the WT strain. However, we detected no differences in growth between WT and $\Delta f c s$ when they were grown in sap harvested from plants infected with the WT or the $\Delta f c s$ mutant (data not shown). Because the $\Delta f c s$ mutant grew normally on these substrates, we infer that HCA were not significant sources of carbon or present in sufficient concentrations to inhibit bacterial growth. 
A

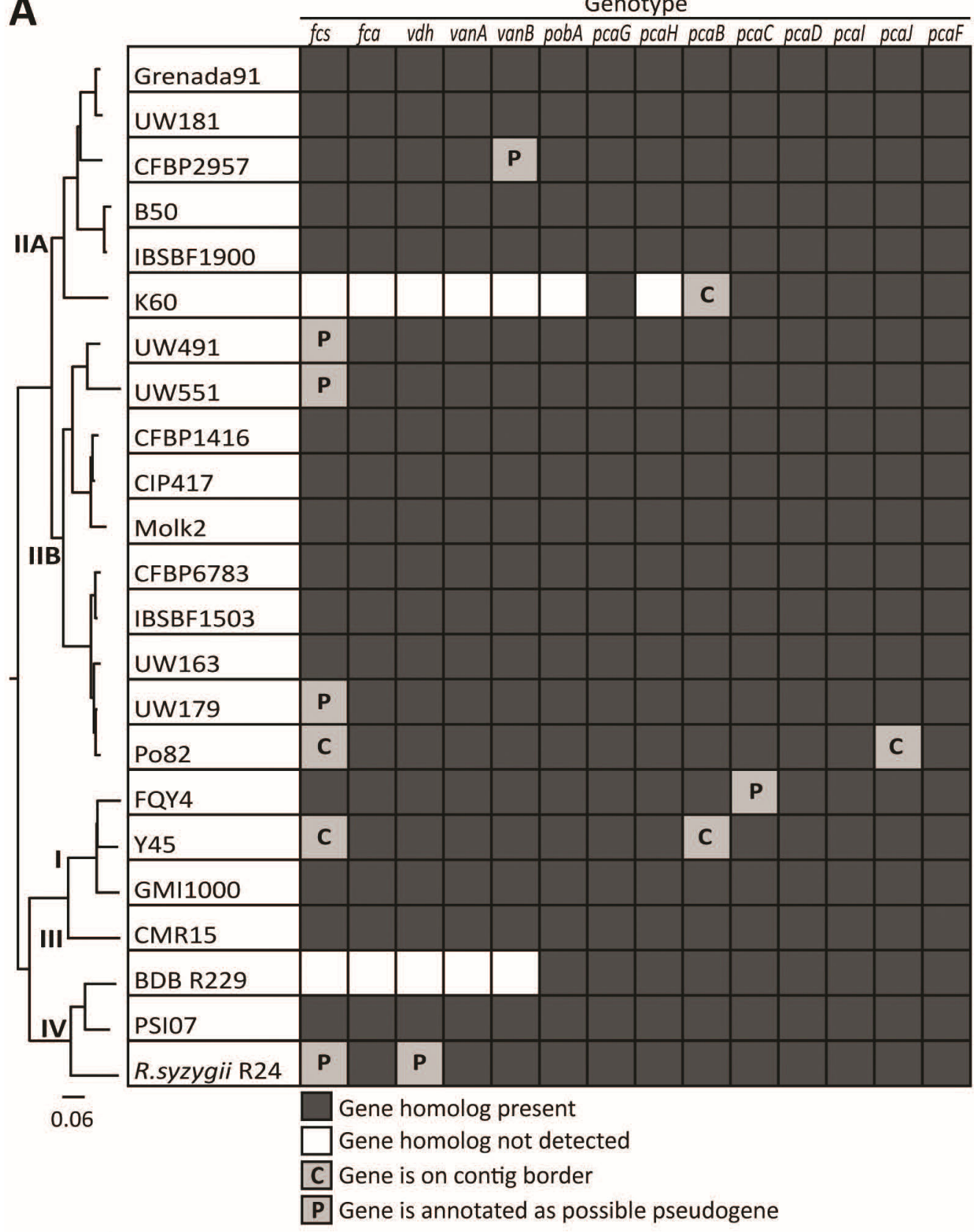

Growth Phenotype

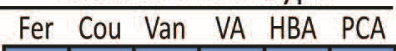

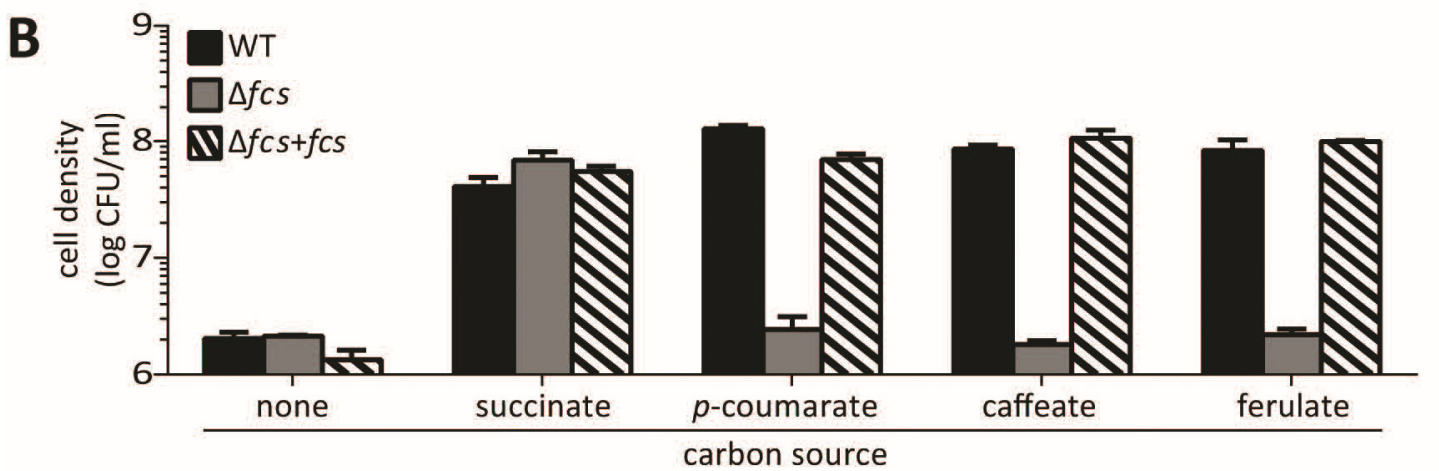

Fig. 2. Hydroxycinnamic acid (HCA) degradation is widely conserved in the Ralstonia solanacearum species complex. A, Genetic and functional conservation of HCA degradation. A whole-genome comparison phylogenetic tree is shown on the left. Presence of HCA degradation genes and growth of $R$. solanacearum strains on ferulate (Fer), p-coumarate (Cou), vanillin (Van), vanillate (VA), p-hydroxybenzoate (HBA), and protocatechuate (PCA) are indicated Blocks marked with superscript a indicate growth phenotype that differs from genotype prediction. B, The $f c s$ gene encodes a functional feruloyl-CoA synthetase in strain GMI1000. Strains were grown in minimal media supplemented with $0.2 \mathrm{mM}$ succinate, $p$-coumarate, caffeate, ferulate, or no carbon for 72 h. Bars represent the mean of three biological replicates and error bars indicate standard error of the mean. 
HCA degradation contributes to colonization of tomato roots.

Studies of $R$. solanacearum growth in potting soil extract, root exudate from sterile seedlings, and xylem sap cannot fully reflect the complex process of invading and multiplying in hosts. Therefore, we transitioned to whole-plant assays. To measure
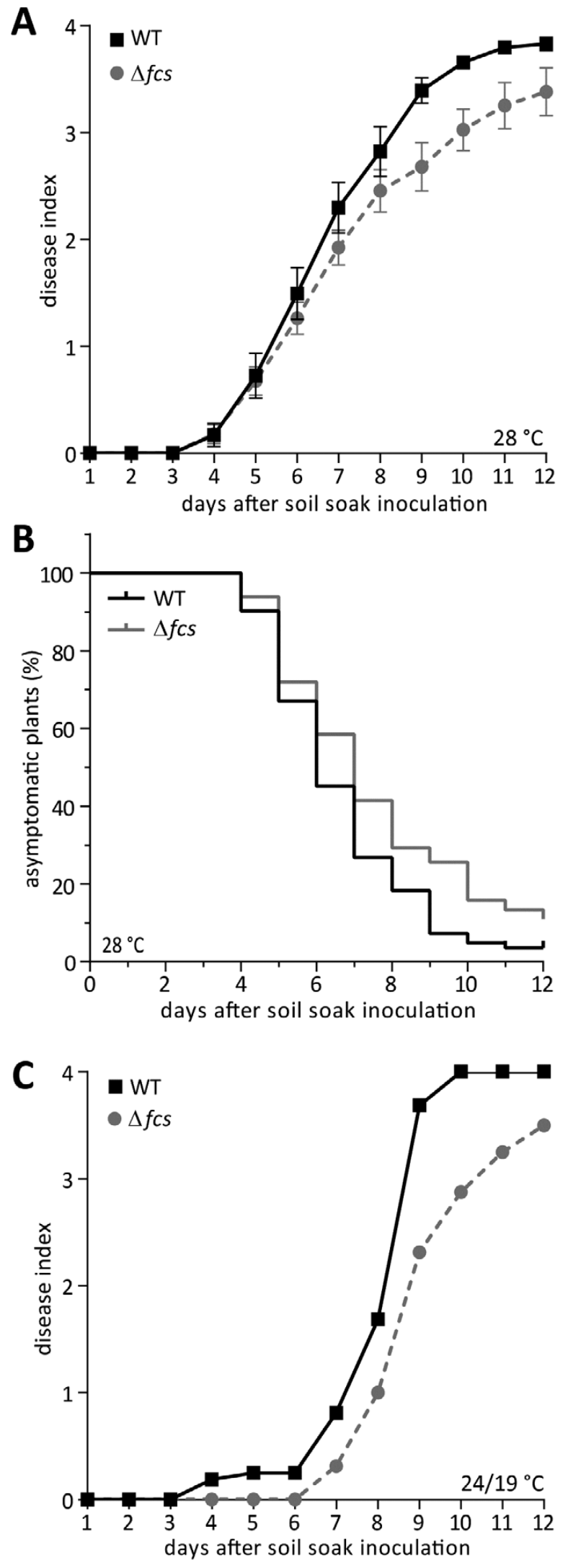

the overall fitness of the $\Delta f c s$ mutant in a naturalistic infection, we used a competition assay where plants were co-inoculated with a $1: 1$ suspension of WT and $\Delta f c s$ mutant bacteria using the soil-soaking method. At the first sign of wilt symptoms, we quantified the population size of each strain in the midstem (Fig. $5 \mathrm{~A})$. With a median competitive index (CI) of 0.46 , the $\Delta f c s$ mutant was significantly less fit than WT bacteria (Wilcoxon signed rank test; $P<0.0001)$. The WT strain outcompeted the $\Delta f c s$ mutant by 2.2 -fold. This assay requires strains to compete during several stages of the $R$. solanacearum infection cycle: survival in bulk soil and colonization of host rhizosphere, roots, and stems. The cumulative effects of these competitive interactions are assessed by comparing population sizes of the two strains in tomato stems. The observed reduced competitive fitness of the $\Delta f c s$ mutant indicates that HCA degradation contributes to at least one stage of the $R$. solanacearum infection cycle.

To more narrowly investigate the role of HCA degradation in early stages of infection, we individually soil-soak inoculated tomato plants with gentamicin-marked WT and $\Delta f c s$ bacteria and quantified population sizes of the strains in surfacesterilized roots (Fig. 5B). At 3 days postinoculation (dpi), the population sizes of the $\Delta f c s$ mutant were lower than those of WT bacteria in roots $(P<0.0094, t$ test $)$ but, by $6 \mathrm{dpi}$, the population size of the mutant caught up to WT levels. These results indicate that HCA degradation contributed significantly to $R$. solanacearum's ability to enter or grow within the root.

To investigate the role of HCA degradation when the bacterium is in tomato stems, we used a two-pronged approach. First we quantified population sizes of the WT and $\Delta f c s$ strains in the midstem stem after individual soil-soak inoculations (Fig. 5C). At 3 dpi, few stems were colonized with detectable levels of bacteria. At $6 \mathrm{dpi}$, the average stem population size of WT bacteria was slightly but insignificantly higher than that of the $\Delta f c s$ mutant. We next used an in planta competition assay that can reveal subtle colonization defects that are missed in individual colonization assays (Macho et al. 2010; Yao and Allen 2006). For this assay, 2,000 CFU of reciprocally-marked WT and $\Delta f c s$ bacteria were co-inoculated into tomato plants via a cut petiole. At symptom onset, the midstem population size of each strain was determined by grinding stem tissue and dilution plating. The population size of the WT strain was slightly larger than that of the $\Delta f c s$ mutant in this in-stem competition assay but the two strains were not significantly different. Overall, colonization assays indicated that HCA degradation may improve stem colonization and showed that HCA degradation contributed significantly to the bacterium's ability to colonize roots.

\section{R. solanacearum HCA degradation does not detectably affect quantity or distribution of lignin in susceptible tomato stems.}

As phenylpropanoids, HCA are precursors to many plant physical defenses, such as diferulate cross-links in primary cell

Fig. 3. Hydroxycinnamic acid (HCA) degradation is required for full virulence of Ralstonia solanacearum. A, Disease progress of wild-type (WT) and $\Delta f c s$ mutant strains on susceptible tomato plants grown at $28^{\circ} \mathrm{C}$. Twenty-one-day-old unwounded plants ('Bonny Best') grown at constant $28^{\circ} \mathrm{C}$ were inoculated by pouring a bacterial suspension into the soil of each pot. Symptoms were rated using a 0-to-4 disease index scale. Each point represents the mean disease index of a total of 82 plants per strain in six biological replicates. Bars indicate standard error of the mean. Disease progress of the $\Delta f c s$ mutant was significantly slower than that of WT ( $P=$ 0.0123 , two-way repeated measures analysis of variance). B, Survival analysis of the above dataset showing the rate of symptom onset after inoculations with WT and the $\Delta f c s$ mutant. $\mathbf{C}$, Disease progress of strains on tomato plants grown in a $24^{\circ} \mathrm{C}$ day and $19^{\circ} \mathrm{C}$ night cycle (one biological replicate, with $n=16$ plants per strain). 
walls and lignin in secondary cell walls. Plant hosts often respond to pathogens by increasing biosynthesis and deposition of phenylpropanoids (Dixon and Paiva 1995). Previous studies found that bacterial wilt-resistant tomato plants express phenylpropanoid biosynthesis genes early during $R$. solanacearum infections (Vanitha et al. 2009). We hypothesized that HCA degradation by the pathogen may reduce or prevent lignin formation by decreasing the pool of lignin precursors (HCA). To test this prediction, we used the acetyl bromide assay to measure gross lignin amounts in whole stems from healthy tomato plants and from plants infected with WT or $\Delta f c s$ bacteria. The lignin content in stems of the wilt-susceptible 'Bonny Best' tomato did not increase in response to infection with either $R$. solanacearum strain (Fig. 6A). Analysis of whole stems could overlook variation in lignin distribution between conditions but a histopathological analysis of stem cross sections using the lignin-specific stain phloroglucinol revealed that lignin was similarly distributed in all samples, mainly around the xylem vessels in the vascular bundles (Fig. 6B to D). This result suggested that $R$. solanacearum's HCA degradation pathway does not detectably alter the amount or the distribution of host lignin, at least under the conditions tested.

These experiments did not determine whether HCA degradation affects the amount of diferulate cross-links in the primary cell wall. Several plant pathogens with large repertoires of cell-wall-degrading enzymes use feruloyl esterases to cleave ferulate from cell wall sugars (Balcerzak et al. 2012; DiGuistini et al. 2011; Hassan and Hugouvieux-Cotte-Pattat 2011). It is possible that $R$. solanacearum encounters diferulate bridges when entering roots or when degrading pit membranes between xylem vessels. Therefore, we tested for feruloyl esterase activity by growing WT strain GMI1000 on an HCA-glucoside analog, ethyl-ferulate. The strain could not use ethyl-ferulate as a sole carbon source (data not shown), which indicates a lack of feruloyl esterase activity. To test whether HCA degradation helps $R$. solanacearum pass through pit membranes and spread in
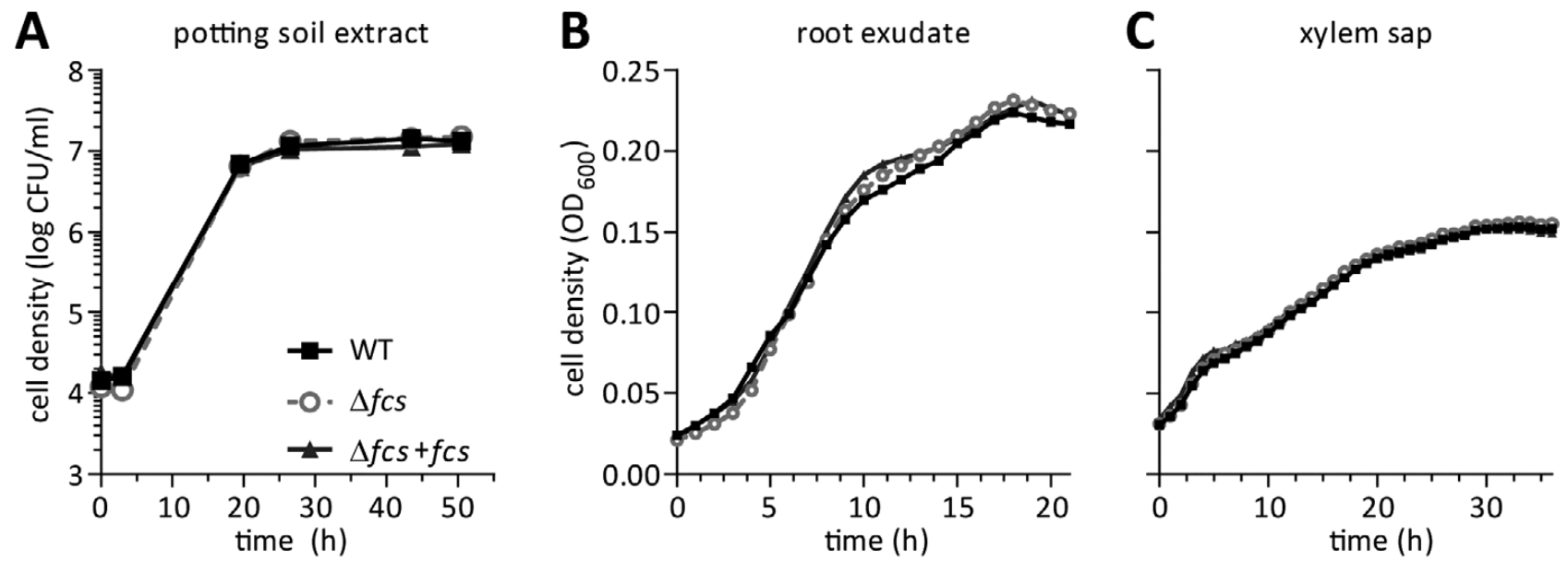

Fig. 4. Hydroxycinnamic acid degradation does not enhance Ralstonia solanacearum growth in plant associated environments. Ex vivo bacterial growth in A, water extract of potting soil; $\mathbf{B}$, tomato root exudate; and $\mathbf{C}$, tomato xylem sap harvested from stems of uninoculated, healthy plants. Graphs show the mean of three replicates.

A

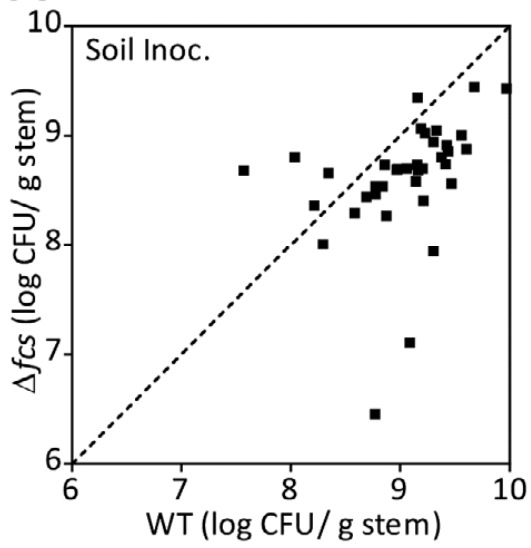

B

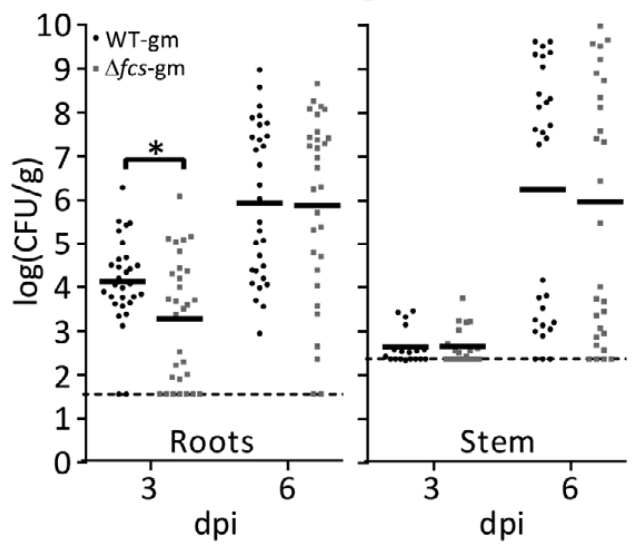

D

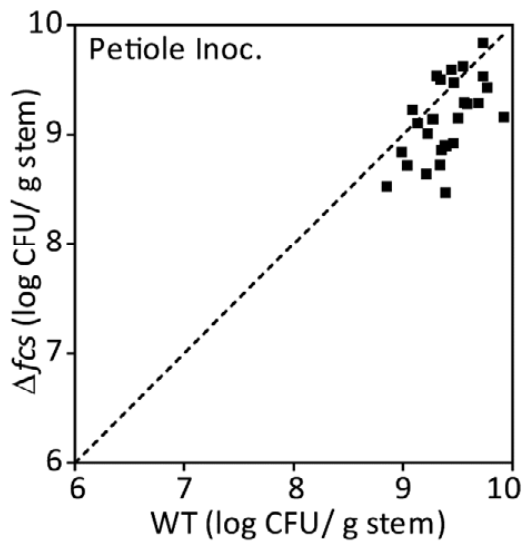

Fig. 5. Hydroxycinnamic acid (HCA) degradation contributes to root entry and competitive fitness following soil-soak inoculation of tomato. A, Competitive fitness of WT vs. $\Delta f c s$ bacteria following soil-soak inoculation. Tomato plants were co-inoculated with mixtures of reciprocally-marked WT and $\Delta f c s$ strains. At the first stage of disease (less than $25 \%$ leaves wilted), midstem tissue was harvested, ground, and dilution plated. Population size of each strain was normalized by initial inoculum. Median competitive index (CI) of the $\Delta f c s$ mutant was $0.46(P<0.0001$, Wilcoxon Signed Rank Test; $n=13$ plants per co-inoculation, 26 total). B and $\mathbf{C}$, Plants grown at $28^{\circ} \mathrm{C}$ were soil-soak inoculated with suspensions of wild-type (WT) or $\Delta f c s$ bacteria. At 3 and 6 days postinoculation (dpi), B, $300 \mathrm{mg}$ of root tissue or $\mathbf{C}, 100 \mathrm{mg}$ of midstem tissue were harvested, ground, and dilution plated to determine cell density of Ralstonia solanacearum ( $n=30$ plants for root colonization at 3 and $6 \mathrm{dpi} ; n=20$ for stem colonization at 3 dpi and $n=30$ at 6 dpi); Solid lines represent the median population sizes and the dashed lines represent the limit of detection. WT-gm colonized roots better than $\Delta f c s$-gm at 3 dpi $(P<0.0094 ; t$ test). D, Competition of $\Delta f c s$ and WT bacteria in tomato stem following direct stem inoculation. Tomato plants were co-inoculated via a cut leaf petiole with 4,000 CFU in a 1:1 suspension of reciprocally-marked WT and $\Delta f c s$ strains. Midstem tissue was harvested at the first sign of symptoms, ground, and dilution plated. Population size of each strain was normalized by initial inoculum. Median CI of the $\Delta f c s$ mutant was $0.71(P=0.225$, Wilcoxon Signed Rank Test; $n=14$ plants per co-inoculation, 28 total $)$. 
tomato stem, WT and $\Delta f c s$ mutant strains were directly inoculated into the xylem of 4-week-old tomato plants via a cut petiole. At 6 to $10 \mathrm{dpi}$, bacterial population sizes were quantified by grinding and dilution plating stem tissue harvested at the point of inoculation and distal sites $(3$ and $6 \mathrm{~cm}$ above the point of inoculation). There were no strain-to-strain differences in population sizes in the distal stem (data not shown). These results suggest that HCA degradation does not measurably contribute to $R$. solanacearum spread in tomato stems.

\section{HCA degradation protects $R$. solanacearum} from caffeate and $p$-coumarate toxicity.

HCA are broadly toxic to microbes. They can directly disrupt membrane integrity, and they are converted to reactive quinones under oxidative conditions, such as after a reactive oxygen species burst during infection of a eukaryotic host (Fitzgerald et al. 2004; Li and Steffens 2002). We hypothesized that $R$. solanacearum uses its HCA degradation pathway to detoxify these potentially lethal chemicals. Using a minimum inhibitory concentration (MIC) growth assay, we compared growth of WT and $\Delta f c s$ bacteria in the presence of increasing concentrations of the three HCA: p-coumarate, caffeate, and ferulate. For WT, the MICs of the $p$-coumarate and caffeate were $1,500 \mu \mathrm{M}$ and the MIC of ferulate was 3,000 $\mu \mathrm{M}$ (Fig. 7). The growth of the $\Delta f c s$ mutant was dramatically reduced relative to growth of the WT strain at sub-MIC con- centrations of both $p$-coumarate and caffeate, with the $\Delta f c s$ mutant showing a significant growth defect in as little as $23 \mu \mathrm{M}$ $p$-coumarate and caffeate. The $\Delta f c s$ mutant suffered near-complete growth inhibition at $375 \mu \mathrm{M} p$-coumarate even though WT bacteria were unaffected by this concentration (Fig. 7A and B). In contrast, there was no difference in growth between WT and $\Delta f c s$ bacteria at any ferulate concentration (Fig. 7C). Adding a WT copy of the putative $f c s$ operon to the mutant restored full WT levels of $p$-coumarate and caffeate tolerance to the complemented strain. Together, these results suggested that HCA degradation protects $R$. solanacearum from toxicity of caffeate and $p$-coumarate but not ferulate.

\section{DISCUSSION}

Plant-associated bacteria experience a complex cocktail of secondary metabolites produced by their eukaryotic hosts. Some of these compounds may provide nutrition, while many are inhibitory or toxic. We found that the ability to degrade a group of such compounds, the HCA, is a quantitative virulence factor for $R$. solanacearum. More specific analyses revealed that HCA degradation contributes to bacterial wilt pathogenesis, possibly by protecting the pathogen from inhibition by toxic HCA during root colonization.

Several lines of evidence support our model that HCA degradation contributes to $R$. solanacearum fitness at early stages
A

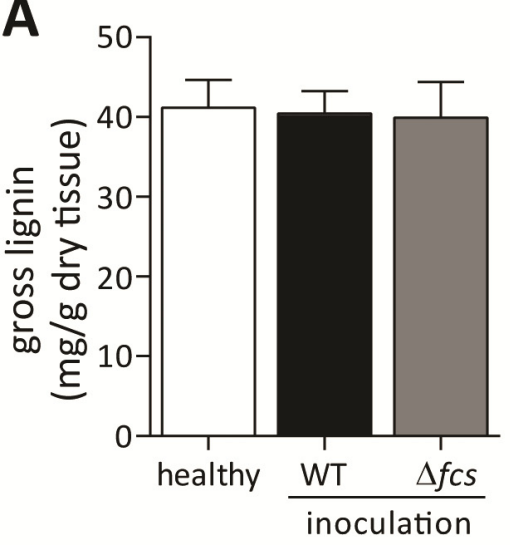

B

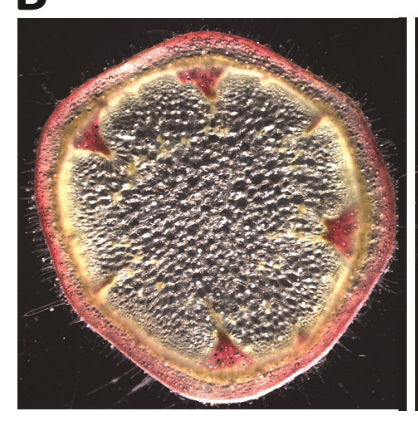

healthy
C

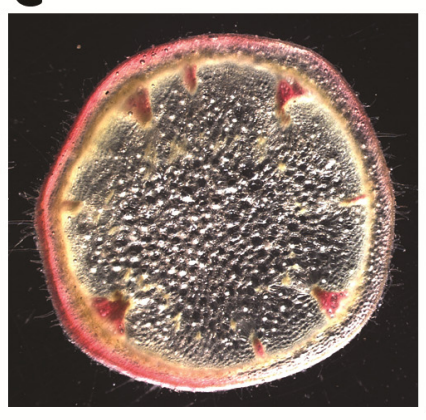

WT-inoculated
D

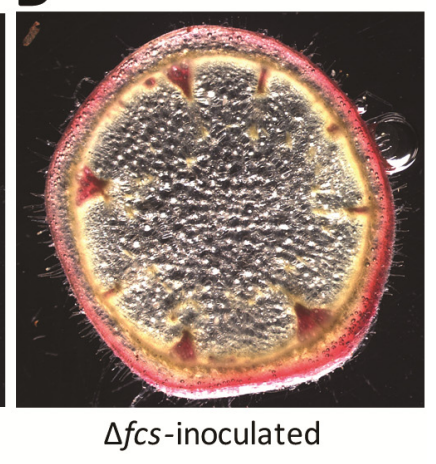

Fig. 6. Hydroxycinnamic acid (HCA) degradation by Ralstonia solanacearum did not affect total lignin quantity or distribution in tomato stems. A, Mean gross lignin content in tomato stems at 6 days post-soil soak inoculation. Whole stems of healthy (mock-inoculated) or infected tomato plants $(n=6$ per condition) were dried, ground, and analyzed by the acetyl bromide lignin quantification assay using wood pulp inulin as a standard. Error bars indicate standard error of the mean. Similar results were obtained at 3 and 9 days after inoculation. B to D, Phloroglucinol HCl-stained cross-sections of stems from representative healthy or symptomatic infected plants. Pink precipitate indicates lignin.
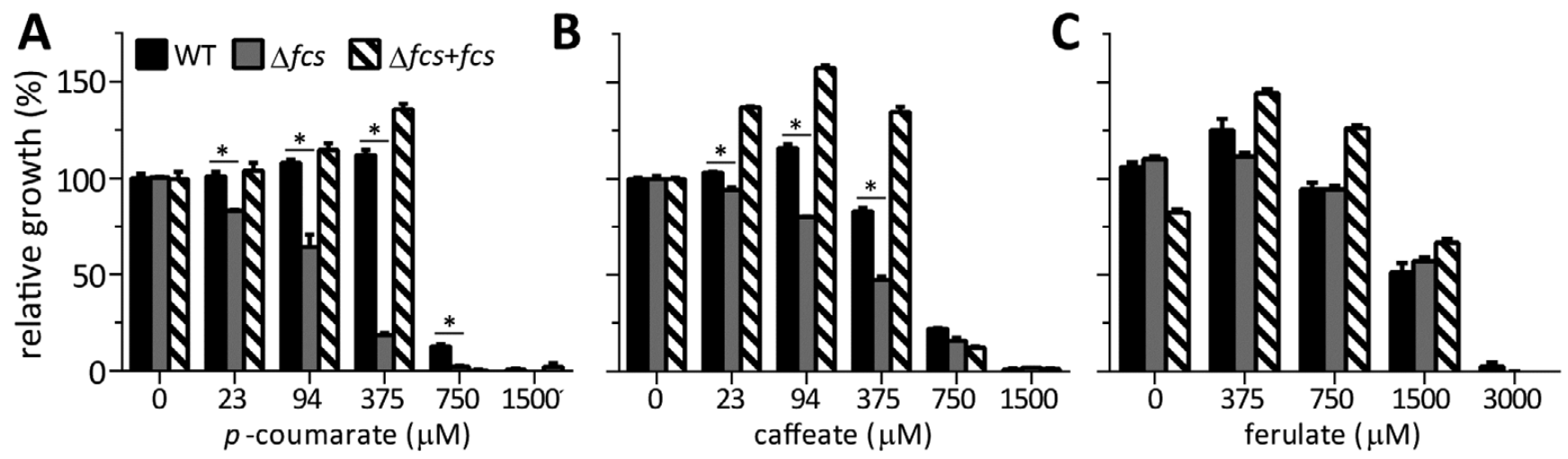

Fig. 7. Hydroxycinnamic acid (HCA) degradation protected Ralstonia solanacearum from HCA toxicity. Bacterial growth in succinate minimal medium supplemented with increasing concentrations of $\mathbf{A}$, $p$-coumarate; $\mathbf{B}$, caffeate; or $\mathbf{C}$, ferulate. Culture optical density was measured by a plate reader 48 h after inoculation with $10^{5} \mathrm{CFU} / \mathrm{ml}$ of bacteria. Growth of each strain was calculated relative to that of wild-type (WT) bacteria growing without HCA. Error bars indicate standard error of the mean. The WT strain was less inhibited than the $\Delta f c s$ mutant by $p$-coumarate and caffeate $(t$ test; $P<0.005)$. 
of disease. First, we found that the HCA degradation and $\beta$ ketoadipate pathways are found predominantly in soil-inhabiting bacteria. In contrast, we did not detect conservation of HCA degradation genes in the xylem-colonizing bacteria Clavibacter michiganensis, Xylella fastidiosa, D. dadantii, or Erwinia amylovora. Second, the virulence defect of the $\Delta f c s$ mutant includes a delay in the first appearance of symptoms. The delay in symptom onset likely results from this mutant's slower colonization of host roots. Surprisingly, the delay in root colonization by the $\Delta f c s$ mutant did not result in smaller eventual population sizes in the stems of infected plants. This suggests that, once the pathogen gains entry to xylem vessels, a strain unable to degrade HCA can grow to the same final density as its WT parent. Thus, HCA degradation appears to be most useful to $R$. solanacearum in host roots and rhizospheres.

Our in vitro inhibition assay demonstrates that the mutant is more susceptible to toxicity of certain HCA. Although the HCA concentrations required for growth inhibition in vitro are 10- to 100-fold higher than concentrations measured in planta, concentrations of these compounds in the xylem of roots and stems may be locally high where phenolics are released by sentinel phenolic-storing-cells (Alvarez et al. 2008; Beckman 2000; Mandal and Mitra 2008; Wallis and Chen 2012). Additionally, the metabolic state of $R$. solanacearum cells affected their susceptibility to HCA. HCA were more inhibitory when $R$. solanacearum was grown in glucose minimal media than when grown in succinate minimal media (data not shown). Moreover, it takes less HCA to inhibit microbial growth when HCA are present in mixtures than when only one HCA is present (Harris et al. 2010). R. solanacearum cells likely encounter mixtures of HCA and other antimicrobial compounds when infecting plants. Therefore, it is possible that the effective inhibitory concentrations of caffeate and $p$-coumarate are lower in the complex chemical environment of an infected plant than in a single-chemical in vitro MIC assay.

Surprisingly, HCA degradation ability did not affect the toxicity of ferulate. $R$. solanacearum may have an $f c s$-independent pathway that specifically degrades ferulate, although this seems unlikely because the $\Delta f c s$ mutant could not grow on ferulate. Alternatively, $R$. solanacearum could have a drug efflux pump that is highly effective at removing ferulate but less active on caffeate and $p$-coumarate. The drug efflux pumps encoded by $\operatorname{din} F$ and acrA are very important for strain K60's virulence on tomato (Brown et al. 2007). The acrA mutant had heightened susceptibility to caffeate toxicity but other HCA were not tested. Strain K60 lacks the HCA degradation pathway; therefore, it would be interesting to determine whether drug efflux pumps also protect other $R$. solanacearum strains from toxicity of caffeate and other HCA.

Our virulence studies used a single strain, GMI1000, but the capacity to degrade HCA is genetically well conserved across the $R$. solanacearum species complex. Although bioinformatic analysis accurately predicted the ability of strains to grow on various HCA compounds $83 \%$ of the time, several strains did not grow on all predicted HCA carbon sources. These disparities demonstrate that predictions based on genomic analysis require functional validation, especially to confirm enzyme substrate specificity (Airola et al. 2014). The multistrain screen for HCA degradation ability revealed several surprising results. Although CFBP2957 and Molk2 grew on ferulate, they did not grow on ferulate degradation intermediates. It is possible that higher sensitivity to toxicity of vanillin and vanillate prevented these strains from growing. Alternatively, vanillin and vanillate may not induce expression of $v d h$ and $v a n A B$ genes as these compounds appear to do in most $R$. solanacearum strains. Pseudogenization of the $f c s$ gene in the race 3 biovar 2 strains (UW491 and UW551) appears to prevent this strain from growing on most metabolites upstream of protocatechuate. This is in contrast to strain GMI1000, where deletion of $f c s$ did not affect growth on any compounds besides HCA.

Although $R$. solanacearum expresses its HCA degradation genes in stem xylem vessels during tomato pathogenesis, these genes are only expressed at moderate levels (Jacobs et al. 2012). It is not surprising that HCA degradation genes were not identified in our previous in vivo expression technology screen for root-exudate-induced genes because that study used $R$. solanacearum K60, which has lost HCA degradation ability (Colburn-Clifford and Allen 2010). Transcriptional analysis could be used to compare expression of HCA degradation genes at different stages in the $R$. solanacearum life cycle, particularly in the rhizosphere. Phenolics in root exudate are chemoattractants for many rhizosphere bacteria, including Agrobacterium tumefaciens (Mandal et al. 2010). Chemotaxis allows $R$. solanacearum to locate host plants but it remains to be determined whether root-exuded phenolics serve as chemoattractants (Yao and Allen 2006).

Plant phenolics influence expression of virulence genes in many plant mutualists and pathogens. Ferulate and other phenolics induce expression of Agrobacterium vir genes, and flavonoids induce Rhizobium nod genes, both of which are required for association with plants (Bhattacharya et al. 2010). Expression of the $D$. dadantii type III secretion genes is induced by the phenolics $o$-coumarate and trans-cinnamate and repressed by $p$ coumarate ( $\mathrm{Li}$ et al. 2009; Yang et al. 2008). We cannot rule out the possibility that the virulence defect of the $\Delta f c s$ mutant is due to HCA-mediated repression of the pathogen's type III secretion system, although such repression cannot be complete because the $\Delta f c s$ mutant still triggers a hypersensitive response in the nonhost tobacco (data not shown).

In response to pathogen attack, plants can reinforce cell walls with lignin, which is an HCA polymer. Although we did not identify an obvious difference in stem lignin in susceptible tomato after $R$. solanacearum infections, we cannot rule out subtle but biologically important differences that would be undetectable in our gross analyses. Moreover, this trait may play an important role in resistant tomato cultivars. A previous study observed increased lignification in response to $R$. solanacearum infections in the quantitatively wilt-resistant tomato 'LS-89' but not in susceptible tomato 'Ponderosa' (Ishihara et al. 2012). Histopathological studies of resistant and susceptible tomato found that $R$. solanacearum colonized fewer xylem vessels in wilt-resistant varieties (Grimault et al. 1994; Rahman et al. 1999). Therefore, it is possible that physical barriers to pathogen spread may be a component of tomato resistance to bacterial wilt.

Taken together, our results indicate that $R$. solanacearum's ability to enzymatically disarm HCA contributes to the success of this widespread pathogen. Pathogens have adopted multiple strategies to evade plant defense compounds. $P$. syringae uses type III effectors to manipulate plant phenylpropanoids (Truman et al. 2006). Many plant pathogens protect themselves with drug efflux pumps, while others enzymatically degrade the plant defense compounds pisatin, tomatine, and HCA (Brown et al. 2007; Michielse et al. 2012 Seipke and Loria 2008; Tegos et al. 2002; Tegtmeier and VanEtten 1982). Our results support a general model that root-infecting pathogens encounter toxic concentrations of HCA, and that degradation of these defenses is important for pathogenic success.

\section{MATERIALS AND METHODS}

\section{Cultures and stock solutions.}

The bacterial strains and plasmids used in this study are described in Table 1. Escherichia coli was grown in Luria-Bertani 
medium at $37^{\circ} \mathrm{C}$. $R$. solanacearum was grown in CPG (casamino acids, peptone, glucose) broth or tetrazolium chloride (TZC) plates at $28^{\circ} \mathrm{C}$ (Kelman 1954). When appropriate, the antibiotics gentamicin (15 mg/liter), kanamycin ( $25 \mathrm{mg} / \mathrm{liter}$ ), and ampicillin $(50 \mathrm{~m} /$ liter $)$ were added. Boucher's minimal medium (BMM) buffered with $10 \mathrm{mM}$ 2-(N-morpholino) ethanesulfonic acid (MES) ( $\mathrm{pH} 5.5$ or 7.0) was used as a minimal medium (Boucher et al. 1985). For sampling from the soil or roots, $R$. solanacearum was plated on modified SMSA (semiselective media, South Africa: peptone at $10 \mathrm{~g} /$ liter, glycerol at $5 \mathrm{ml} / \mathrm{liter}$, casamino acids at $1 \mathrm{~g} / \mathrm{liter}$, crystal violet at $2.5 \mathrm{mg} /$ liter, TZC at $2.5 \mathrm{mg} / \mathrm{liter}$, bacitracin at $13 \mathrm{mg} / \mathrm{liter}$, penicillin at $0.3 \mathrm{mg} / \mathrm{liter}$, chloramphenicol at $2.5 \mathrm{mg} / \mathrm{liter}$, and cycloheximide at $25 \mathrm{mg} /$ liter) (Engelbrecht 1994). Stock solutions of phenolic compounds were prepared in DMSO. Chemicals were from Sigma-Aldrich, Fisher Scientific, or Difco Laboratories.

A plate assay was used to detect HCA degradation ability in $20 R$. solanacearum isolates. BMM MES pH 7.0 plates were supplemented with $1 \mathrm{mM}$ succinate, ferulate, $p$-coumarate, vanillin, vanillate, or $p$-hydroxybenzoate, or $5 \mathrm{mM}$ protocatechuate. Compound concentration was chosen empirically because there was a trade-off between compound toxicity at high concentrations and minimal bacterial growth at low concentrations. To assess growth, $2 \mu \mathrm{l}$ of a dense overnight culture of each strain was spotted onto the plates. After incubation at $28^{\circ} \mathrm{C}$ for 3 to 5 days, growth of the strains on each substrate was assessed relative to growth on BMM plates without supplemented carbon. In several cases, plate growth phenotypes were indeterminate or contradicted predictions from genomic data. Therefore, growth was further tested by culturing these strains for $48 \mathrm{~h}$ in liquid BMM with the relevant carbon source and quantifying cell density by dilution plating.

\section{Plant growth conditions.}

Wilt-susceptible tomato plants (Bonny Best) were grown in Sunshine Redimix professional growing mix at $28^{\circ} \mathrm{C}$ in a climate controlled growth chamber with a 12-h day and night cycle. To test virulence during cool conditions, plants were grown in a climate controlled chamber with a cycle of 24 and $19^{\circ} \mathrm{C}$ (day and night, respectively). Plants were watered with Hoagland solution.

Genomic analysis of $\boldsymbol{R}$. solanacearum species complex and identification of HCA degradation gene homologs.

The phylogenetic tree was designed around a matrix of genomic distances obtained using the Maximum Unique Match index (MUMi) algorithm (Deloger et al. 2009). MUMi values were computed from pairwise genome comparisons made with MUMMer 3.0 (Kurtz et al. 2004). The distances were then clustered together into a tree using the neighborjoining method (Saitou and Nei 1987).

We identified homologs of the GMI1000 and UW551 HCA degradation pathway using the OMA algorithm with translated coding sequences from the genomes of the other $R$. solanacearum isolates (Altenhoff et al. 2011).

\section{Strain construction.}

The $\Delta f c s$ strain was created using a $s a c B$ suicide vector designed to precisely excise the $f c s$ ORF. Briefly, we amplified approximately $1-\mathrm{kb}$ regions directly upstream $\left(f c s \mathrm{KOupF}: 5^{\prime}\right.$ CTCGACGATGCGGACCTG-3'; fcsKOupR: 5'-GACAGCGA CCTCGCATCAG-3') and downstream (fcsKOdwnF: $5^{\prime}$-ctca tgcgaggtcgctgtcGAGTGTTGAGCGGGGCC-3'; $f c s$ KOdwnR: 5'-GGAAGGCGAATTCGAGCG-3') of the $f c s$ ORF by polymerase chain reaction (PCR), fused the fragments by splice by overlap extension PCR (SOE-PCR) (Heckman and Pease 2007), and blunt-end ligated them into the pCR-blunt subcloning vector (Life Technologies). This knockout construct was transferred by restriction digestion and ligation to the $s a c B$ vector pUFR80 to create pUFR80- $f$ csKO (Castañeda et al. 2005). $R$. solanacearum GMI1000 (WT) was transformed with pUFR80$f c s \mathrm{KO}$ by electroporation and plated on kanamycin media to select for merodiploids that were sucrose sensitive and kanamycin resistant. A clone was then counterselected on $\mathrm{CPG}+5 \%$ sucrose to select for excision of the $s a c B$-containing vector backbone. This process either restored the WT genotype or yielded a markerless deletion of the $f c s$ ORF. Colony PCR using fcsKOupF and fcsKOdwnR primers was used to screen for loss of the $f c s$ ORF.

Table 1. Strains and plasmids used in this study

\begin{tabular}{|c|c|c|}
\hline Strain or plasmid & Relevant characteristics $^{\mathbf{a}}$ & Source or reference \\
\hline \multicolumn{3}{|l|}{ Strains } \\
\hline Escherichia coli TOP10 & 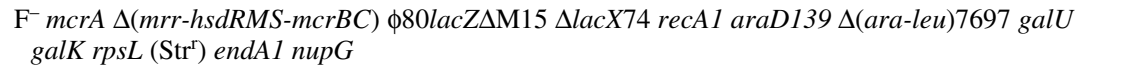 & Life Technologies \\
\hline \multicolumn{3}{|l|}{ Ralstonia solanacearum } \\
\hline GMI1000 (WT) & Wild-type, phylotype I & Boucher et al. 1985 \\
\hline GMI1000-Gm & GMI1000 transformed with pRCG-GWY, Gm ${ }^{\mathrm{r}}$ & This study \\
\hline GMI1000-Km & GMI1000 transformed with pRCK-GWY, Kan ${ }^{\mathrm{r}}$ & This study \\
\hline$\Delta f c s$ & GMI1000 with unmarked, precise deletion of the feruloyl-CoA synthetase $(f c s)$ ORF & This study \\
\hline$\Delta f c s-\mathrm{Gm}$ & $\Delta f c s$ transformed with pRCG-GWY, $\mathrm{Gm}^{\mathrm{r}}$ & This study \\
\hline$\Delta f c s-\mathrm{Km}$ & $\Delta f c s$ transformed with pRCK-GWY, $\mathrm{Kan}^{\mathrm{r}}$ & This study \\
\hline$\Delta f c s+f c s$ & $\begin{array}{l}\text { Complemented } \Delta f c s \text { with } \mathrm{Tn} 7 \mathrm{FcsComp} \text { integrated into chromosome at the selectively neutral } \\
\text { att site, } \mathrm{Gm}^{\mathrm{r}}\end{array}$ & This study \\
\hline \multicolumn{3}{|c|}{ ( } \\
\hline pRCG-GWY & Vector that integrates downstream of $g \operatorname{lm} S$ on the GMI1000 chromosome, $\mathrm{Gm}^{\mathrm{r}}$ & Monteiro et al. 2012 \\
\hline pRCK-GWY & Vector that integrates downstream of $\operatorname{glm} S$ on the GMI1000 chromosome, $\mathrm{Kan}^{\mathrm{r}}$ & Monteiro et al. 2012 \\
\hline pCR-blunt & Cloning vector & Life Technologies \\
\hline pUFR80 & pUFR80, $\mathrm{Suc}^{\mathrm{s}}(\mathrm{s} a c B), \mathrm{Kan}^{\mathrm{r}}$ & Castañeda et al. 2005 \\
\hline pUC18T-miniTn7T-Gm & Vector that integrates into selectively neutral att site on $R$. solanacearum chromosome $\mathrm{Gm}^{\mathrm{r}}, \mathrm{Amp}^{\mathrm{r}}$ & Choi et al. 2005 \\
\hline pTNS1 & $\begin{array}{l}\text { Helper plasmid for pUC18T-miniTn7T-Gm encoding the site-specific TnsABCD Tn7 transposase, } \\
\text { Amp }\end{array}$ & Choi et al. 2005 \\
\hline pUFR80-fcsKO & pUFR80 $+f c s$ markerless deletion construct inserted into sacI/xbaI sites in MCS, Suc ${ }^{\mathrm{s}}(\operatorname{sacB}), \mathrm{Kan}^{\mathrm{r}}$ & \\
\hline pMiniTn7FcsComp & $\begin{array}{l}f c s \text { operon }(f c a-v d h-f c s) \text { with native promoter cloned into hindIII/speI sites in pUC18T-miniTn7T- } \\
\text { Gm, } \mathrm{Gm}^{\mathrm{r}}, \mathrm{Amp}^{\mathrm{r}}\end{array}$ & $\begin{array}{l}\text { This study } \\
\text { This study }\end{array}$ \\
\hline
\end{tabular}


A miniTn7 vector was used to complement the $\Delta f c s$ strain (Choi et al. 2005). The miniTn7 transposon integrates into the selectively neutral att site downstream of $\mathrm{glmS}$. We amplified the 5.6-kb putative operon encompassing $500 \mathrm{bp}$ upstream of $f c a$, the $f c a$ ORF, the $v d h$ ORF, and the $f c s$ ORF using primers fcsoperonF (5'-TGCACCAGGACCAATACCTC-3') and fcsoperonR (5'-CTCAACGTGTTCCCCATCCA-3'). The resulting PCR product was subcloned into pCR-blunt and transferred by restriction enzyme digestion and ligation into pUC18t-miniTn7-Gm to create pTn7fcsComp. The $\Delta f c s R$. solanacearum strain was transformed with pMiniTn 7 fcsComp and the helper vector pTNS1 encoding the transposase TnsABC+D and plated on gentamicin media. Complementation was confirmed by restoration of the ability to grow on HCA.

To create antibiotic-marked strains for colonization and competition assays, GMI1000 and the $\Delta f c s$ strain were transformed with the chromosomal insertion vectors pRCG-GWY or pRCK-GWY carrying gentamicin or kanamycin cassettes, respectively (Monteiro et al. 2012).

\section{Virulence assay.}

To assess virulence following soil-soak inoculation, 17- to 21-day old plants with unwounded roots were inoculated by pouring bacterial suspensions into the soil to a final concentration of $1 \times 10^{8} \mathrm{CFU} / \mathrm{g}$ soil (Tans-Kersten et al. 1998). Symptoms on each plant were rated daily using a disease index scale of 0 to 4 , corresponding to wilt severity of $0=$ asymptomatic plants, $1=$ less than $25 \%, 2=$ less than $50 \%, 3=$ less than $75 \%$, and $4=$ up to $100 \%$ leaves wilted.

\section{Colonization and competition assays.}

To assess colonization ability of individual strains, plants were soil-soak inoculated with either WT-Gm or $\Delta f c s-\mathrm{Gm}$. At 3 and $6 \mathrm{dpi}$, bacterial populations were determined in surfacesterilized root and midstem stem tissue. To surface sterilize the roots, soil was removed by gentle shaking and washing. Then, roots were swirled in a $10 \%$ bleach solution for $15 \mathrm{~s}$ and rinsed three times in successive water baths to remove remaining bleach. Roots were sectioned into evenly distributed slices totaling $0.3 \mathrm{~g}$. From the same plants, a 0.1 -g midstem stem slice was sampled. Tissue was ground in water with $0.28-\mathrm{mm}$ metal beads using a homogenizer (MoBio). Stem grinding required two cycles and root grinding required three cycles of 2,200 rpm for $1.5 \mathrm{~min}$, with a 4-min rest between cycles. Homogenized root and stem tissue were dilution plated onto SMSA and CPG with gentamicin, respectively.

A competition assay was used to investigate subtler differences in stem colonization ability (Yao and Allen 2006). For soil-soak inoculations, plants were inoculated with a 1:1 mixture of antibiotic-marked WT: $\Delta f c s$ bacteria totaling $1 \times 10^{8}$ $\mathrm{CFU} / \mathrm{g}$ soil. Marker swapping was used to ensure that competitive fitness differences were not caused by the antibiotic resistance marker: thus, a set of plants was inoculated with a WT-Gm $+\Delta f c s-\mathrm{Km}$ mixture and another set was inoculated with a WT-Km $+\Delta f c s$-Gm mixture. Antibiotic markers did not significantly impact the fitness of either strain (Supplementary Fig. S1). At the first sign of wilt symptoms (disease index =1), plants were harvested and population sizes of each strain in the stem were determined by grinding and dilution plating on selective media. Population size was normalized to initial inoculum of each strain. Then, CI was calculated by dividing the normalized $\Delta f c s$ population size by the normalized WT population size from the same plant. For cut-petiole inoculations, bacteria were directly introduced into the stem by placing a 2$\mu \mathrm{l}$ drop of bacterial suspension onto a freshly cut petiole. Each plant was inoculated with 4,000 cells in a $1: 1$ mixture of marked WT and $\Delta f c s$ bacteria.
Growth in xylem sap, root exudate, and potting soil extract.

Xylem sap was collected from healthy and soil-soak-inoculated plants displaying the first signs of symptoms, as previously described (HCA et al. 2012). Plants were detopped with a sharp blade, and sap was allowed to pool on the stump by root pressure. The first drop was discarded to avoid contamination by cell debris, and the stump was rinsed with water and blotted dry. Sap was only collected for 30 min to avoid damage-response-induced changes in sap composition. Samples were flash-frozen and kept at $-80^{\circ} \mathrm{C}$ until use. Growth of strains took place on $0.2 \mu \mathrm{M}$ filter-sterilized xylem sap, and root exudate was measured in a plate reader (Bio-Tek). Overnight cultures were washed and adjusted to an optical density at $600 \mathrm{~nm}$ of 1.0. In a half-area 96-well plate (Corning), $45 \mu \mathrm{l}$ of each growth substrate was combined with $5 \mu \mathrm{l}$ of bacterial suspensions. Optical density was measured hourly until growth plateaued. Each experiment was repeated twice.

Root exudate was collected as described (Yao and Allen 2006). Briefly, seed were sterilized and germinated on $1 \%$ water agar plates in the dark for 3 days. Sterile roots were transferred into a $50-\mathrm{ml}$ conical tube containing $5 \mathrm{ml}$ of BMM with $10 \mathrm{mM}$ MES, $\mathrm{pH}$ 7.0. Tubes were incubated in the dark for $24 \mathrm{~h}$, and root exudate was used immediately as previous studies reported loss of potency with time.

To collect water-soluble potting soil extract, $1 \mathrm{~g}$ of potting soil was suspended in $50 \mathrm{ml}$ of distilled water in a $50-\mathrm{ml}$ conical tube and incubated horizontally with shaking for $2 \mathrm{~h}$ at room temperature (Smolander et al. 2005). Filtered potting soil extract was used immediately. Dense overnight cultures were washed, and $0.5 \mu \mathrm{l}$ of the cell suspension was inoculated into 5 $\mathrm{ml}$ of potting soil extract. Cell density was determined periodically by dilution plating.

\section{Lignin quantification and visualization.}

Tomato plants (21 days old) were left healthy or inoculated by pouring WT or $\Delta f c s$ bacteria into the soil to a final concentration of $1 \times 10^{8} \mathrm{CFU} / \mathrm{g}$ of soil. Total stem was harvested 3, 6, and 9 dpi and desiccated, yielding approximately $30 \mathrm{mg}$ dry weight/plant. Total lignin was quantified by the spectroscopic acetyl bromide assay (Fukushima and Hatfield 2004). Wood pulp inulin was used as a lignin standard. Lignin in cross-sections of tomato stems was stained by phloroglucinol: $\mathrm{HCl}$ (Nakano and Meshitsuka 1992).

\section{Growth inhibition assay.}

A growth inhibition assay modified from the standard MIC assay was used to test the toxicity of HCA (Brown et al. 2007). BMM MES pH $5.5+10 \mathrm{mM}$ succinate supplemented with 23 to $3,000 \mu \mathrm{M}$ ferulate, caffeate, or $p$-coumarate or with no inhibiting compound was inoculated with bacterial strains to $1 \times 10^{5}$ $\mathrm{CFU} / \mathrm{ml}$ final concentration. After incubating strains at $28^{\circ} \mathrm{C}$ with shaking, cell density was measured by optical density in a Bio-Tek plate reader. Growth of strains in each condition was calculated relative to growth of the WT strain without inhibitory HCA.

\section{ACKNOWLEDGMENTS}

We thank P. Weimer for help with lignin analysis; M. Kabbage for help with microscopy; F. van Gijsegem, D. Khokhani, and P. Prior for valuable discussions; and B. Fochs for technical help. This research was supported by the United States Department of Agriculture (USDA) Agricultural Research Service Floral and Nursery Crops Research Initiative and the University of Wisconsin-Madison College of Agricultural and Life Sciences. T. M. Lowe was supported by National Institute of Health National Research Service Award T32 GM07215 and by an Agriculture and Food 
Research Initiative Competitive Grant from the USDA National Institute of Food and Agriculture.

\section{LITERATURE CITED}

Abdelkafi, S., Sayadi, S., Gam, A., Ben, Z., Casalot, L., and Labat, M. 2006. Bioconversion of ferulic acid to vanillic acid by Halomonas elongata isolated from table-olive fermentation. FEMS (Fed. Eur. Microbiol. Soc.) Microbiol. Lett. 262:115-120.

Airola, M. V., Tumolo, J. M., Snider, J., and Hannun, Y. A. 2014. Identification and biochemical characterization of an acid sphingomyelinaselike protein from the bacterial plant pathogen Ralstonia solanacearum that hydrolyzes ATP to AMP but not sphingomyelin to ceramide. PLoS One 9:e105830

Altenhoff, A. M., Schneider, A., Gonnet, G. H., and Dessimoz, C. 2011 OMA 2011: Orthology inference among 1000 complete genomes. Nucleic Acids Res. 39:D289-D294.

Alvarez, S., Marsh, E. L., Schroeder, S. G., and Schachtman, D. P. 2008. Metabolomic and proteomic changes in the xylem sap of maize under drought. Plant Cell Environ. 31:325-340.

Balcerzak, M., Harris, L. J., Subramaniam, R., and Ouellet, T. 2012. The feruloyl esterase gene family of Fusarium graminearum is differentially regulated by aromatic compounds and hosts. Fungal Biol. 116:478-488.

Beckman, C. H. 2000. Phenolic-storing cells: Keys to programmed cell death and periderm formation in wilt disease resistance and in general defence responses in plants? Physiol. Mol. Plant Pathol. 57:101-110.

Bhattacharya, A., Sood, P., and Citovsky, V. 2010. The roles of plant phenolics in defence and communication during Agrobacterium and Rhizobium infection. Mol. Plant Pathol. 11:705-719.

Boucher, C., Barberis, P., Trigalet, A., and Demery, D. 1985. Transposon mutagenesis of Pseudomonas solanacearum: Isolation of Tn5-induced avirulent mutants. J. Gen. Microbiol. 131:2449-2457.

Brown, D. G., Swanson, J. K., and Allen, C. 2007. Two host-induced Ralstonia solanacearum genes, acrA and $\operatorname{din} F$, encode multidrug efflux pumps and contribute to bacterial wilt virulence. Appl. Environ. Microbiol. 73:2777-2786

Campillo, T., Renoud, S., Kerzaon, I., Vial, L., Baude, J., Gaillard, V., Bellvert, F., Chamignon, C., Comte, G., and Nesme, X. 2014. Analysis of hydroxycinnamic acid degradation in Agrobacterium fabrum reveals a coenzyme A-dependent, beta-oxidative deacetylation pathway. Appl. Environ. Microbiol. 80:3341-3349.

Campos, L., Lisón, P., López-Gresa, M. P., Rodrigo, I., Zacarés, L., Conejero, V., and Bellés, J. M. 2014. Transgenic tomato plants overexpressing tyramine N-hydroxycinnamoyltransferase exhibit elevated hydroxycinnamic acid amide levels and enhanced resistance to Pseudomonas syringae. Mol. Plant-Microbe Interact. 27:1159-1169.

Cao, Y., Tian, B., Liu, Y., Cai, L., Wang, H., Lu, N., Wang, M., Shang, S., Luo, Z., and Shi, J. 2013. Genome sequencing of Ralstonia solanacearum FQY_4, isolated from a bacterial wilt nursery used for breeding crop resistance. Genome Announc. 1:e00125-00113.

Castañeda, A., Reddy, J. D., El-Yacoubi, B., and Gabriel, D. W. 2005. Mutagenesis of all eight avr genes in Xanthomonas campestris pv. campestris had no detected effect on pathogenicity, but one avr gene affected race specificity. Mol. Plant-Microbe Interact. 18:1306-1317.

Choi, K.-H., Gaynor, J. B., White, K. G., Lopez, C., Bosio, C. M., KarkhoffSchweizer, R. R., and Schweizer, H. P. 2005. A Tn7-based broad-range bacterial cloning and expression system. Nat. Methods 2:443-448.

Colburn-Clifford, J., and Allen, C. 2010. A cbb3-type cytochrome C oxidase contributes to Ralstonia solanacearum R3bv2 growth in microaerobic environments and to bacterial wilt disease development in tomato. Mol. Plant-Microbe Interact. 23:1042-1052.

Deloger, M., El Karoui, M., and Petit, M. A. 2009. A genomic distance based on MUM indicates discontinuity between most bacterial species and genera. J. Bacteriol. 191:91-99.

DiGuistini, S., Wang, Y., Liao, N. Y., Taylor, G., Tanguay, P., Feau, N., Henrissat, B., Chan, S. K., Hesse-Orce, U., and Alamouti, S. M. 2011. Genome and transcriptome analyses of the mountain pine beetle-fungal symbiont Grosmannia clavigera, a lodgepole pine pathogen. Proc. Natl. Acad. Sci. U.S.A. 108:2504-2509.

Dixon, R. A., and Paiva, N. L. 1995. Stress-induced phenylpropanoid metabolism. Plant Cell 7:1085-1097.

Elphinstone, J. G. 2005. The current bacterial wilt situation: A global overview. Pages 9-28 in: Bacterial Wilt: The Disease and the Ralstonia solanacearum Species Complex. C. Allen, P. Prior, and A.C. Hayward, eds. American Phytopathological Society Press, St Paul, MN. U.S.A.

Engelbrecht, M. 1994. Modification of a semi-selective medium for the isolation and quantification of Pseudomonas solanacearum. Bacterial Wilt Newsl. 10:3-5.

Fitzgerald, D., Stratford, M., Gasson, M., Ueckert, J., Bos, A., and Narbad,
A. 2004. Mode of antimicrobial action of vanillin against Escherichia coli, Lactobacillus plantarum and Listeria innocua. J. Appl. Microbiol. 97:104-113.

Fry, S. C., Willis, S. C., and Paterson, A. E. 2000. Intraprotoplasmic and wall-localised formation of arabinoxylan-bound diferulates and larger ferulate coupling-products in maize cell-suspension cultures. Planta 211:679-692

Fukushima, R. S., and Hatfield, R. D. 2004. Comparison of the acetyl bromide spectrophotometric method with other analytical lignin methods for determining lignin concentration in forage samples. J. Agric. Food Chem. 52:3713-3720.

Gabriel, D. W., Allen, C., Schell, M., Denny, T. P., Greenberg, J. T., Duan, Y. P., Flores-Cruz, Z., Huang, Q., Clifford, J. M., Presting, G., González, E. T., Reddy, J., Elphinstone, J., Swanson, J., Yao, J., Mulholland, V., Liu, L., Farmerie, W., Patnaikuni, M., Balogh, B., Norman, D., Alvarez, A., Castillo, J. A., Jones, J., Saddler, G., Walunas, T., Zhukov, A., and Mikhailova, N. 2006. Identification of open reading frames unique to a select agent: Ralstonia solanacearum race 3 biovar 2. Mol. PlantMicrobe Interact. 19:69-79.

Grimault, V., Gelie, B., Lemattre, M., Prior, P., and Schmit, J. 1994. Comparative histology of resistant and susceptible tomato cultivars infected by Pseudomonas solanacearum. Physiol. Mol. Plant Pathol. 44:105123.

Harris, V., Jiranek, V., Ford, C. M., and Grbin, P. R. 2010. Inhibitory effect of hydroxycinnamic acids on Dekkera spp. Appl. Microbiol. Biotechnol. 86:721-729.

Hassan, S., and Hugouvieux-Cotte-Pattat, N. 2011. Identification of two feruloyl esterases in Dickeya dadantii 3937 and induction of the major feruloyl esterase and of pectate lyases by ferulic acid. J. Bacteriol. 193:963-970.

Heckman, K. L., and Pease, L. R. 2007. Gene splicing and mutagenesis by PCR-driven overlap extension. Nat. Protocols 2:924-932.

Ishihara, T., Mitsuhara, I., Takahashi, H., and Nakaho, K. 2012. Transcriptome analysis of quantitative resistance-specific response upon Ralstonia solanacearum infection in tomato. PLoS One 7:e46763.

Ishimaru, Y., Kakei, Y., Shimo, H., Bashir, K., Sato, Y., Sato, Y., Uozumi, N., Nakanishi, H., and Nishizawa, N. K. 2011. A rice phenolic efflux transporter is essential for solubilizing precipitated apoplasmic iron in the plant stele. J. Biol. Chem. 286:24649-24655.

HCA, J. M., Babujee, L., Meng, F., Milling, A., and Allen, C. 2012. The in planta transcriptome of Ralstonia solanacearum: Conserved physiological and virulence strategies during bacterial wilt of tomato. mBio 3:e0114-00112.

Kelman, A. 1954. The relationship of pathogenicity of Pseudomonas solanacearum to colony appearance in tetrazolium medium. Phytopathology 44:693-695.

Kim, D., Kim, S. W., Choi, K. Y., Lee, J. S., and Kim, E. 2008. Molecular cloning and functional characterization of the genes encoding benzoate and $p$-hydroxybenzoate degradation by the halophilic Chromohalobacter sp. strain HS-2. FEMS (Fed. Eur. Microbiol. Soc.) Microbiol. Lett. 280:235-241.

Kurtz, S., Phillippy, A., Delcher, A. L., Smoot, M., Shumway, M., Antonescu, C., and Salzberg, S. L. 2004. Versatile and open software for comparing large genomes. Genome Biol. 5:R12.

Lanoue, A., Burlat, V., Henkes, G. J., Koch, I., Schurr, U., and Röse, U. S. 2010. De novo biosynthesis of defense root exudates in response to Fusarium attack in barley. New Phytol. 185:577-588.

Li, L., and Steffens, J. C. 2002. Overexpression of polyphenol oxidase in transgenic tomato plants results in enhanced bacterial disease resistance. Planta 215:239-247.

Li, Z., Wu, S., Bai, X., Liu, Y., Lu, J., Liu, Y., Xiao, B., Lu, X., and Fan, L. 2011. Genome sequence of the tobacco bacterial wilt pathogen Ralstonia solanacearum. J. Bacteriol. 193:6088-6089.

Macho, A. P., Guidot, A., Barberis, P., Beuzón, C. R., and Genin, S. 2010. A competitive index assay identifies several Ralstonia solanacearum type III effector mutant strains with reduced fitness in host plants. Mol. Plant-Microbe Interact. 23:1197-1205.

Mandal, S., and Mitra, A. 2008. Accumulation of cell wall-bound phenolic metabolites and their upliftment in hairy root cultures of tomato ( $\mathrm{Lyco}$ persicon esculentum Mill.). Biotechnol. Lett. 30:1253-1258.

Mandal, S. M., Chakraborty, D., and Dey, S. 2010. Phenolic acids act as signaling molecules in plant-microbe symbioses. Plant Signal. Behav. 5:359-368.

Michielse, C. B., Reijnen, L., Olivain, C., Alabouvette, C., and Rep, M. 2012. Degradation of aromatic compounds through the $\beta$-ketoadipate pathway is required for pathogenicity of the tomato wilt pathogen Fusarium oxysporum f. sp. lycopersici. Mol. Plant Pathol. 13:10891100

Monteiro, F., Solé, M., van Dijk, I., and Valls, M. 2012. A chromosomal insertion toolbox for promoter probing, mutant complementation, and 
pathogenicity studies in Ralstonia solanacearum. Mol. Plant-Microbe Interact. 25:557-568.

Mueller, W., and Beckman, C. 1984. Ultrastructure of the cell wall of vessel contact cells in the xylem of tomato stems. Ann. Bot. 53:107-114.

Nakaho, K., Hibino, H., and Miyagawa, H. 2000. Possible mechanisms limiting movement of Ralstonia solanacearum in resistant tomato tissues. J. Phytopathol. 148:181-190.

Nakano, J., and Meshitsuka, G. 1992. The detection of lignin. Pages 23-32 in: Methods Lignin Chemistry. S. Y. Lin and C. W. Dence, eds. Springer-Verlag, Berlin.

Naoumkina, M. A., Zhao, Q., Gallego-Giraldo, L., Dai, X., Zhao, P. X., and Dixon, R. A. 2010. Genome-wide analysis of phenylpropanoid defence pathways. Mol. Plant Pathol. 11:829-846.

Narbad, A., and Gasson, M. J. 1998. Metabolism of ferulic acid via vanillin using a novel CoA-dependent pathway in a newly-isolated strain of Pseudomonas fluorescens. Microbiology 144:1397-1405.

Neumann, G., and Römheld, V. 2007. The release of root exudates as affected by the plant physiological status. Pages 23-72 in: The Rhizosphere Biochemistry and Organic Substances at the Soil-Plant Interface. R. Pinton, Z. Veranini, and P. Nannipieri, eds. CRC Press, New York.

Parke, D., and Ornston, L. N. 2003. Hydroxycinnamate (hca) catabolic genes from Acinetobacter sp. strain ADP1 are repressed by HcaR and are induced by hydroxycinnamoyl-coenzyme A thioesters. Appl. Environ. Microbiol. 69:5398-5409.

Peeters, N., Guidot, A., Vailleau, F., and Valls, M. 2013. Ralstonia solanacearum, a widespread bacterial plant pathogen in the post-genomic era. Mol. Plant Pathol. 14:651-662.

Pérez-Pantoja, D., De la Iglesia, R., Pieper, D. H., and González, B. 2008. Metabolic reconstruction of aromatic compounds degradation from the genome of the amazing pollutant-degrading bacterium Cupriavidus necator JMP134. FEMS (Fed. Eur. Microbiol. Soc.) Microbiol. Rev. 32:736-794.

Plaggenborg, R., Overhage, J., Steinbüchel, A., and Priefert, H. 2003. Functional analyses of genes involved in the metabolism of ferulic acid in Pseudomonas putida KT2440. Appl. Microbiol. Biotechnol. 61:528535.

Rahman, M. A., Abdullah, H., and Vanhaeke, M. 1999. Histopathology of susceptible and resistant Capsicum annuum cultivars infected with Ralstonia solanacearum. J. Phytopathol. 147:129-140.

Remenant, B., Coupat-Goutaland, B., Guidot, A., Cellier, G., Wicker, E., Allen, C., Fegan, M., Pruvost, O., Elbaz, M., Calteau, A., Salvignol, G., Mornico, D., Mangenot, S., Barbe, V., Médigue, C., and Prior, P. 2010. Genomes of three tomato pathogens within the Ralstonia solanacearum species complex reveal significant evolutionary divergence. BMC Genomics 11:379

Remenant, B., Cambiaire, J.-C. D., Cellier, G., Barbe, V., Medigue, C., Jacobs, J. M., Fegan, M., Allen, C., and Prior, P. 2011. Phylotype IV strains of Ralstonia solanacearum, R. syzygii and the Blood Disease Bacterium form a single genomic species despite their divergent lifestyles. PLoS One 6:e24356.

Remenant, B., Babujee, L., Lajus, A., Médigue, C., Prior, P., and Allen, C.
2012. Sequencing of K60, type strain of the major plant pathogen $\mathrm{Ral}$ stonia solanacearum. J. Bacteriol. 194:2742-2743.

Romero-Silva, M. J., Méndez, V., Agullo, L., and Seeger, M. 2013. Genomic and functional analyses of the gentisate and protocatechuate ring-cleavage pathways and related 3-hydroxybenzoate and 4-hydroxybenzoate peripheral pathways in Burkholderia xenovorans LB400. PloS One 8:e56038.

Saitou, N., and Nei, M. 1987. The neighbor-joining method: A new method for reconstructing phylogenetic trees. Mol. Biol. Evol. 4:406-425.

Salanoubat, M., Genin, S., Artiguenave, F., Gouzy, J., Mangenot, S., Arlat, M., Billault, A., Brottier, P., Camus, J. C., Cattolico, L., Chandler, M., Choisne, N., Claudel-Renard, C., Cunnac, S., Demange, N., Gaspin, C., Lavie, M., Moisan, A., Robert, C., Saurin, W., Schiex, T., Siguier, P., Thebault, P., Whalen, M., Wincker, P., Levy, M., Weissenbach, J., and Boucher, C. A. 2002. Genome sequence of the plant pathogen Ralstonia solanacearum. Nature 415:497-502.

Seipke, R. F., and Loria, R. 2008. Streptomyces scabies 87-22 possesses a functional tomatinase. J. Bacteriol. 190:7684-7692.

Smolander, A., Loponen, J., Suominen, K., and Kitunen, V. 2005. Organic matter characteristics and $\mathrm{C}$ and $\mathrm{N}$ transformations in the humus layer under two tree species, Betula pendula and Picea abies. Soil Biol. Biochem. 37:1309-1318.

Tans-Kersten, J., Guan, Y., and Allen, C. 1998. Ralstonia solanacearum pectin methylesterase is required for growth on methylated pectin but not for bacterial wilt virulence. Appl. Environ. Microbiol. 64:4918-4923.

Tegos, G., Stermitz, F. R., Lomovskaya, O., and Lewis, K. 2002. Multidrug pump inhibitors uncover remarkable activity of plant antimicrobials Antimicrob. Agents Chemother. 46:3133-3141.

Tegtmeier, K., and VanEtten, H. 1982. The role of pisatin tolerance and degradation in the virulence of Nectria haematococca on peas: A genetic analysis. Phytopathology 72:608-612.

Truman, W., Zabala, M. T., and Grant, M. 2006. Type III effectors orchestrate a complex interplay between transcriptional networks to modify basal defence responses during pathogenesis and resistance. Plant J. 46:14-33.

Vanitha, S. C., Niranjana, S. R., and Umesha, S. 2009. Role of phenylalanine ammonia lyase and polyphenol oxidase in host resistance to bacterial wilt of tomato. J. Phytopathol. 157:552-557.

Wallis, C. M., and Chen, J. 2012. Grapevine phenolic compounds in xylem sap and tissues are significantly altered during infection by Xylella fastidiosa. Phytopathology 102:816-826.

Wicker, E., Grassart, L., Coranson-Beaudu, R., Mian, D., Guilbaud, C., Fegan, M., and Prior, P. 2007. Ralstonia solanacearum strains from Martinique (French West Indies) exhibiting a new pathogenic potential. Appl. Environ. Microbiol. 73:6790-6801.

Xu, J., Zheng, H.-J., Liu, L., Pan, Z.-C., Prior, P., Tang, B., Xu, J.-S., Zhang, H., Tian, Q., and Zhang, L.-Q. 2011. The complete genome sequence of plant pathogen Ralstonia solanacearum strain Po82. J. Bacteriol. 193:4261-4262.

Yao, J., and Allen, C. 2006. Chemotaxis is required for virulence and competitive fitness of the bacterial wilt pathogen Ralstonia solanacearum. J. Bacteriol. 188:3697-3708. 